GROUPE D'ANALYSE ET DE THÉORIE ÉCONOMIQUE LYON - ST ÉTIENNE

GTIE

WP 1314

Value judgments and economics expertise

Antoinette Baujard

March 2013 


\section{GATE Groupe d'Analyse et de Théorie Économique Lyon-St Étienne}

93, chemin des Mouilles 69130 Ecully - France

Tel. +33(0)4 72866060

Fax $+33(0) 472866090$

6, rue Basse des Rives 42023 Saint-Etienne cedex 02 - France

Tel. +33 (0)4 77421960

Fax. +33 (0)4 77421950

Messagerie électronique / Email : gate@gate.cnrs.fr

Téléchargement / Download : http://www.gate.cnrs.fr - Publications / Working Papers 


\title{
Value judgments and economics expertise
}

\author{
Antoinette Baujard *
}

March 21, 2013

Second version

\begin{abstract}
This paper tackles the problem of the demarcation of value judgments in economic expertise. Is it possible to disentangle values from facts, or neutral scientific assertions from value-laden judgments, in the context of economic expertise? If not, why not? And if it is, under what conditions? First, drawing on concepts from analytic philosophy, the paper highlights the interdependencies between descriptive, evaluative, and prescriptive judgments. Second, drawing notably on social studies of science, the paper proposes a definition of 'expertise', and translates this into a list of successive stages wherein these different types of judgments are involved. A backward analysis of these stages is provided in order to identify where values stand, and who holds them. Third, reconsidering the positions of neutrality in economics (Mongin 2006), the paper defends the 'weak non-neutrality' view in the context of expertise, and concludes with reflections on what could be done to address the problem of democratic legitimacy raised by the difficulty of demarcation.

Key-words: methodology, value judgments, prescription, evaluation, recommendation, expertise, neutrality, demarcation .

JEL-Code: A13, B41, D63

\footnotetext{
* Université de Lyon, Lyon, F-69007 France; CNRS, GATE Lyon Saint-Etienne, Ecully, F-69130, France; Université Jean Monnet, Saint-Etienne, F-42000, France. Contact: antoinette.baujard@univ-st-etienne.fr, (33) +4 77421361 .

$\dagger$ This paper was first presented as a public lecture to the Economics Department of Virginia Tech in Blacksburg, on 20 February 2012. I wish to thank all those who attended the lecture, and in particular Richard Ashley, Sheryll Ball, Michael Moller, and Aris Spanos for a constructive discussion. I am also grateful to Maurice Salles, and especially to Valérie Clément and Philippe Mongin, for reviewing a previous version of this paper, and to Ben Young for help in preparing the manuscript. This research was made possible thanks to Nick Tideman's invitation to Virginia Tech, the donor of the Virginia Tech grant for economic methodology, and the Welfare Economics grant linked to the Chair Université Jean Monnet and CNRS. The usual caveats hold.
} 


\section{Introduction}

There is lively interest in the role of value judgments in economics, as well as the connected issue of the democratic justification of the power of experts. ${ }^{1}$ Even when they do not question the probity or foundations of expert advice, people often believe that democracy is endangered by the power of experts. This happens especially where people feel that decisions on important social issues are being taken not by those who will be directly affected, but rather by experts deciding on their behalf. It is worrying, therefore, to think that experts may be framing their decisions not only by reference to their expert knowledge but also through their own beliefs, values and interests, and that these may be overriding the values of the wider population. An easy way to foreclose debate on this subject would be to ignore the anger of the laymen, to accuse them of ignorance and irrationality, and perhaps even to develop educational programs to convince them to trust the experts (something which we can perhaps see in initiatives to promote the 'social understanding of science'). Such approaches are predicated on neglecting the role of values in public decisions. Consideration of values, however, is central in most public matters pertaining to economics, and hence in the application of public economic expertise: it is difficult to believe that no value-loaded judgments are ever implied by recommendations concerning economic policy. An important issue for democracy thus concerns the possibility of disentangling value judgments from neutral assertions within the context of economic expertise, so as to identify the origin of value judgments in expert recommendations, and to be able to distinguish the actual role played by experts from the role played by politicians - in so far as the latter are considered the legitimate representatives of the people. This is not straightforward, and it shall be referred to henceforth as the "demarcation problem." Taking the demarcation problem seriously is another

\footnotetext{
${ }^{1}$ As an illustration, Amartya Sen recently claimed that: "Several features of policy making are worrying, particularly in Europe. The first is a democratic failure. An economic policy has to be ultimately something that people understand, appreciate and support. That's what democracy is all about. The old idea of "no taxation without representation" is not there in Europe at the moment" (Storbeck and Hess 2012). See also Martimort (2012).
} 
way of tackling public concerns regarding the legitimacy of experts on matters of public economics. Such an analysis, and thus the elaboration of a framework within which to conduct that analysis, constitute necessary steps towards transparency in pursuit of healthy public debate and the improvement of economic methods. We are here dealing with methodological and epistemological issues concerning the integration of value judgments into economics in general, and into public economic expertise in particular. This raises a number of crucial questions, which fall into three broad categories. The first category concerns economists and value judgments: Why should economists care about value judgments? Why should economists work with value judgments? Should economists make value judgments or not? The second category concerns the nature and origin of value judgments themselves: Are value judgments ideological objects which should be ruled out of scientific discourse? Or is there any way in which they may be incorporated into the set of scientific assertions? And where do such value judgments come from? (Or: where should they come from?) From politics, or economics? And can we disentangle the value judgment from the overall judgment regarding a situation? The final set concerns the nature of expertise: What is economic expertise? What is distinctive about the judgment made by an expert in economics as compared with an assertion of economic science in general? Can we apply the discussions on neutrality in economics generally to scrutinize the demarcation problem in economic expertise?

Even without taking into consideration the relevant literature in epistemology or philosophy of science, there are numerous papers within economics itself which discuss the role and status of value judgments (Arrow 1951, Little 1952, Buchanan 1959, Klappholz 1964, Blaug 1980[1995], Heath 1994, among others). This appears to be an area of study in which strong assertions are loudly and passionately made. Many economists think their business should strictly concern mathematical models or factual judgments, and that any problem which calls for value judgments must be excluded from the realm of economic science (see in particular Robbins 1932). Kenneth Boulding (1969) even declared: "saying that economics is a moral science is a contradiction." Some have defended the op- 
posite thesis: on this view, it is part of the specific character of economics, and of social sciences in general, to be permeated with value judgments. Some have even considered economics not only to be a moral science, but a mere expression of ideology (Myrdal 1954). And some have asserted that value judgments

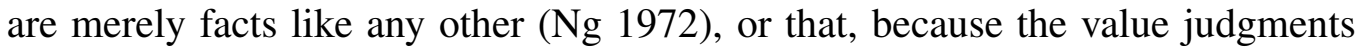
typically made in welfare economics are uncontroversial, they may thus be considered on a par with any positive assertion (Archibald 1959, Hennipman 1976). Some have conducted contextual analyses of the importance of value judgment in the contributions of various authors (e.g. Balisciano and Medema 1999, Davis 2005, Cherrier 2009, Andrews 2010), or textual analyses of the influence of value judgments in allegedly neutral textbooks (e.g. Hill and Myatt 2010). Conversely, and regrettably, fewer papers conduct minute methodological analyses aimed at tracing the role of value judgments in economics (Mongin 2006); and, to my knowledge, no such paper has been concerned specifically with the case of expertise.

The knowledge used by economic experts is of course drawn from economic science; but the specific nature of 'experts', compared with those who otherwise happen to partake of economic knowledge, is that experts have to apply this knowledge in recommending a practical course of action, in response to an official demand. ${ }^{2}$ To clarify the specific character of expertise, the definition we use throughout this paper shall be set by reference to the four following conditions (Encinas de Munagorri and Leclerc 2009). First, that there exists a procedure which is decision-oriented and based on some scientific knowledge. Second, that expertise constitutes the subject of an explicit request, and hence supposes the existence of a separate "client," such that anybody who is not appointed by a client through a formal and legal procedure may not be properly considered an expert. The client may need expertise to frame a more robust decision (e.g. the members of government) or position (e.g. the members of the formal opposition). ${ }^{3}$ Third,

\footnotetext{
${ }^{2}$ I here favor the legal definition of expertise, consistent with the meaning attributed to the word in social studies of science, rather than the layman's meaning which refers to any specific knowledge, competence, or experience.

${ }^{3}$ For the sake of simplicity and clarity, we shall refer to both cases as a "decision," considering
} 
that even though the expert is presumed to possess the knowledge or experience necessary to be able to help the decision maker, knowledge may not be an essential criterion for defining an expert. Fourth (and as a implicit consequence of the third condition), that expertise is called upon for a specific case in a specific context. By contrast, for instance, a court which needed to clarify a general question of scientific knowledge may need to call not an expert but an amicus curiae. All expertise should therefore be seen as concerning applying general knowledge to specific contexts.

On the basis of a definition of expertise as strictly based on these four conditions, I claim that the decision process may be seen as containing three stages, occurring successively. The first stage is the scientific stage where economic science is produced. Second stage is the expertise stage, which includes several sub-stages and involves specific procedures. It supposes, as we said above, a request from a "client" who, unlike the "expert," stands outside the domain of science. The expert then selects the economic knowledge to answer the question which she is hired to address. She applies her knowledge in formulating the answer. The expert is therefore responsible for preparing the decision, which comes at the last stage. Decision makers (e.g. politicians) use information drawn from economic expertise in order to frame their decisions. From this description of the decision process, expertise appears to be the operational center of the prescriptive role played by economists. They are the ones who convey economic science to the decision maker.

Speaking in general terms, we may say that experts' recommendations imply values as well as scientific and factual knowledge. The decision process as a whole involves different kinds of judgments: descriptive, evaluative and prescriptive, the properties of which shall be scrutinized carefully in this paper. It is standardly believed that the scientific stage is concerned with descriptive judgments, that the phases of the expertise stage are characterized by prescriptive judgments, and that the client is responsible for deciding which values should be at stake, as well that selecting what position to hold (e.g. as an Opposition party or a trade union) is in itself a decision. 
as realizing the actual decision. In a simple dichotomy model, value judgments hence arise from clients only, and are taken as ingredients by the experts. This paper intends to show that this model is undermined by deeper analyses of the nature of judgments and of the decision process.

The paper is organized as follows. In section 2, I define the different properties of distinct judgments, highlight their interdependency, and characterize the specific nature of value judgments. In section 3, focusing on expertise and prescriptive judgments, I conduct a backward analysis of the stages of the decision process in order to identify where values come into play, and who eventually holds them. In so doing, I aim to set up an analytical framework which may be useful to other studies concerned with the demarcation between value and factual judgments, and which, at the same time, will also be able to show where such judgments cannot be disentangled. In section 4, reconsidering the positions of neutrality in economics (Mongin 2006), I defend the "weak non-neutrality" view in the context of expertise. I consider what could be done to contribute to the issue of democratic legitimacy raised by the difficulty of demarcation. Section 5 concludes.

\section{Properties of distinct judgments}

I here develop some arguments imported from analytic philosophy. Within economics, and particularly within economic expertise, there are three different types of judgments. First, descriptive judgments which correspond to statements of fact, or "is" propositions. "Sirah is a vine, so is Chardonnay," for instance, is a descriptive judgment. Second, evaluative judgments which correspond to statements of value. The "is" here is thus qualified. "Sirah makes good wine" or "Sirah makes red wine" are instances of evaluative judgments. Third, prescriptive judgments which correspond to statements of either recommendation or obligation. For instance, "Paul should drink Sirah, not Chardonnay" is a prescriptive judgment. This trichotomy seems clear, and the separation between the three dif- 
ferent classes of judgments is clear cut. Let us therefore consider the three types of judgment in turn, with the aim of shaking this first impression, and highlighting rather their interdependency.

(1) Let us begin by casting doubt on the assertion that a description is a mere statement of fact. Consider the following three statements:

i) Paul is choosing Sirah whereas he could also have some Chardonnay.

ii) Paul says he likes Sirah better than Chardonnay.

iii) Paul is choosing Sirah, and notices that Chardonnay is less expensive.

As these three descriptions of a possibly similar situation illustrate, each descriptive assertion requires a selection among all possible descriptions of reality, rather than mere observation (Sen 1980). However, we cannot say that each of these selections a priori involves an appeal to values - as the ideology view would maintain (see below, section 4). At most we may speak of specific interpretations, where the selection depends on the aim of the description. Such interpretations may lead us to pursue certain specific paths of judgment, but this influence is not properly or strictly based on the descriptive judgments themselves. Rather, the evaluation presupposes the selection of a specific description.

(2) Let us now consider the properties of evaluative judgments. An evaluative notion of quality (such as "right," "good," "balanced") supposes certain axiological abstract judgments. For instance, the definition of the "good," "right," or "just" relies on a specific ethical theory; but evaluative judgments are not all of an ethical nature, nor are they only of an ethical nature. Following Williams (1985), we may distinguish between "thin" and "thick" predicates. Thin predicates are strictly evaluative, such as "It is not good (right) to drink wine" or "Sirah is a good wine." Thick predicates are both descriptive and evaluative, such as: "Sirah wines have a balance of integrated, firm tannins and bright acidity with a soft, spicy and lingering finish." Thick predicates include descriptions that go beyond the simple function of providing evaluations; thin predicates do not. Applications of thin predicates do not make sense without also providing either a description or citing an experience. Expertise does indeed suppose the application of an abstract statement to a particular case - this is the fourth condition for defining expertise 
(see above). Hence, experts will use thick predicates in their statements.

How does this argument regarding predicates apply to judgments? I here present the notion of "basicness" as introduced by Sen (1967), and then discuss whether evaluations are basic or non-basic. Sen (1967: 50) defines a value judgment as "basic" to a person if no conceivable revision of factual assumptions can make him revise the judgment. If such revisions can take place, the judgment is "non-basic" in his value system. Judgments are considered basic until the converse is proved. If evaluations were to be considered basic, it would follow that no expertise was needed in order to move from that evaluation to advocating a specific course of action, since no statements of fact or specific attention to the actual situation would be involved in their formulation. It therefore follows that evaluations are non-basic in such case, since, if they were, we could imagine that a computer programmed with an exhaustive list of all the facts and theoretical knowledge (or an amicus curiae, as we said previously) would also be able to answer any such question; but this seems implausible. If they are non-basic, then the request for an expert does make sense, in that she would have to base her conclusions on a prudent judgment. Apart from cases involving strictly abstract predicates, evaluation thus requires that we make descriptive judgments of some kind.

(3) The class of prescriptive judgments is a priori the most important one for describing the judgments of experts, as these are the ones the client is expecting him to formulate. Let us consider their properties: namely, their imperative status, their descriptive content, and their evaluative content.

(3a) Their imperative status is standardly what distinguishes prescriptive judgments from other descriptive and evaluative judgments: they contain some authoritative call for action, or at least some element which orientates action in a certain way. But the link from prescription to action is not absolutely direct and unquestionable, as we shall now see. Consider the following examples of such judgments:

iv) "As Paul prefers Sirah to Chardonnay, he should drink the former rather the 
latter";

v) "Paul ought to drink Sirah";

vi) "Paul, do not drink Chardonnay!"

vii) "Do not drink!"

viii) "No drinking"

These examples belong to different categories of prescriptive judgment. By specifying the context and conditions under which the prescription holds, assertion $i v$ corresponds to some conditional advocacy in favour of certain actions. Such prescriptions correspond to recommendations; they cannot be called imperative - or, at most, we can refer to them as hypothetical and non-compulsive imperatives, implying that the person formulating the prescription would not consider the imperative to have been disobeyed if Paul acted contrary to it. Conversely, assertion $v i$ is an uncontroversial statement of obligation, incorporating an imperative judgment. It may accurately be called imperative, in that the person formulating such a prescription does hope it will be respected. Assertion $v$ corresponds to an ought statement. It is underspecified, and may belong to one or the other class, depending on the context. Assertions vii and viii correspond to a universal imperative, whether explicitly addressed to one person as in vii, or focused on an implied situation as in viii. I therefore defend the claim that there are two distinct kinds of prescriptive judgments: obligations, and recommendations; the former have the status of imperatives, and the latter of hypothetical imperatives.

As this claim is not standard in the analytic philosophy literature, I shall now defend it against the counter view that all prescriptive judgments are imperative. ${ }^{4}$

A first argument in favor of the distinction that I defend may be based on differentiating between the roles we have identified in the description of the chronology of the decision-making process. Let us consider the competing view which holds that all prescriptions are imperative by nature. We may note, first, that experts are not entitled to formulate imperative judgments; if experts were to formulate

\footnotetext{
${ }^{4}$ I shall not, however, address all the different views on prescriptive judgments. See Hare (1952), and notably Hare (1952: 10.3) for further distinctions within the class of prescriptive judgments.
} 
prescriptions with imperative status - i.e., to be followed whatever happens -, the client would be logically committed to follow his recommendations. However, since the clients are the entitled deciders, experts have no legitimacy to take decisions, nor to determine the decisions that the client makes. The distinction of roles between expert and client makes such a scenario unlikely to happen; but to guard against such a confusion of roles, which could arise if we take the imperative nature of prescriptions seriously, experts should content themselves with issuing evaluative judgments. The formulation of prescriptive judgments, strictly speaking, should proceed from the client, who is the proper decision maker. This exclusion of prescriptive vocabulary from expert usage corresponds to an ideal use of the language of morals. However, describing an ideal case is not always the best way to understand how concepts are applied. We do indeed observe that prescriptive language is used by experts, and even that they are expected to use such language. For instance, the French Council for Economic Analysis (Conseil d'analyse économique, or CAE) is explicitly asked to formulate one or two pages of recommendations for certain policies at the end of each of their studies. CAE specifies meanwhile that "the opinions displayed in CAE surveys belong only to their authors and do not commit either the Council, nor the delegated president, nor, of course, the Prime Minister" (see CAE website). It is assumed that the expected use of prescriptive vocabulary does not and should not imply any imperative meaning. The client is the one who decides and who is responsible for formulating the imperative statement. Conversely, the expert formulates an opinion which does not need to be followed, and which is referred to as a recommendation.

Another way to present this argument is as follows. If prescriptions presuppose an obligation, there ought to be some authority to this obligation which is able to lead through to an actual decision. Such statements may suppose that Paul (in cases $i v, v$ and $v i$ ) or anybody concerned (in cases vii and viii) shall indeed have a feeling that they must do as the prescription enjoins, just as if there existed an evaluative notion of the good (or of the "better") that was personally accepted 
by the person concerned, and which would make her follow the prescription. ${ }^{5}$ Individualized obligations are imperative for the person concerned if and only if there exists a principle of authority that establishes a link between the prescriptive statement and the actual decision. Conversely, there is no such necessity for the case of recommendations, since the advisers have no direct authority over actions, even though they are entitled to formulate recommendations for action.

As well as the argument based on the difference between the roles of advisers and deciders, a second argument for the distinction claim may be proposed, this one imported from the philosophy of science. This argument focuses on how experts frame their judgments. An expert formulates his policy recommendation based on his analysis, which is limited on two grounds. First, the framing which is imposed by his appeal to the tools and knowledge of economic science places all other knowledge - inter alia, sociological, political, ethical stakes - as a priori beyond the scope of his analysis. Second, all scientific statements, and especially those of social science, are marked by uncertainty: experts may have done their analysis properly, or they may not. For instance, they may later learn something which would show that they should have used other tools to complete their analysis. Similarly, new theories in economic science may be discovered, or relevant data that were previously unknown or inaccessible may become known and accessible. In all cases, such developments are likely to invalidate aspects of the former statements, or at least to induce their reconsideration or reformulation. Most serious scientists will withhold full commitment from very substantive empirical claims as made at any instant $t$. Meanwhile, and without contradiction, they may have good reasons to trust such statements on the basis of their current analysis - honestly made, let's say, on the basis of sound work, competence, and experience. All in all, they may have good reasons to have faith in their statements, conditional on the restrictions imposed by the disciplinary approach to the issue in question, and upon the limitations of the knowledge they currently have access to.

\footnotetext{
${ }^{5}$ Hare (1952: 167) speaks of a statement of psychological fact.
} 
We now develop a final argument in favor of the distinction claim. As we shall set out below, prescriptions entail certain descriptions. In particular, they imply certain implicit descriptions about what should be done to conform to the standard that people generally accept: to drink what you prefer in case $i v$, to drink what is better for certain reasons in cases $v$ or $v i$, or not to drink at all in the contexts implied in cases vii or viii. Paul is supposed to conform to these expectations just as if there existed an evaluative notion of good or better that is commonly accepted by people. ${ }^{6}$ Obligations as applied to groups imply that such 'sociological facts' do exist, while a recommendation may simply suppose that the client holds that such a case is likely to occur, or that it is worth considering as a reasonable assumption. Concretely, this means that experts may suppose that their clients are likely to want to act according to certain principles of action that the recommendation they formulate is supposed to reflect.

It is therefore necessary to distinguish between two versions of prescriptive judgments: obligations, which correspond to imperative prescriptions; and recommendations, which correspond to non-imperative prescriptions, as in the expertise case.

(3b) Armed with this distinction, let us now scrutinize further statements of prescriptive judgments which rely on other kinds of judgments. These, we will see, do indeed contain both descriptive and evaluative parts.

Firstly, as was noticed in case $i v$, some judgments may make explicit mention of the descriptive context in which the prescription holds, or they may assume there exist descriptive contexts under which the prescription holds. Such judgments do indeed depend on certain facts, which entails that changing the facts could imply changing the judgment. Using Sen's vocabulary, such prescriptions are hence non-basic, in the sense that a "change in factual assumptions would entail her changing judgment" (Sen 1967:50sen1967). Some obligations, however, seem to escape being non-basic: such as the commandment "thou shall not kill," which is supposed to hold in any context. These kinds of judgments, however,

\footnotetext{
${ }^{6}$ Hare (1952: 167) describes this as a statement of sociological fact.
} 
belong to the class of universal imperatives, rather than to the hypothetical imperatives which are proper to the expert's recommendations, and with which we are here concerned.

Besides this, it is controversial to claim that such prescriptions always hold no matter what. Faced with a moral dilemma, we might need to accept that the commandment does not hold in specific cases, for instance for self-defense, or in the choice of killing one fetus out of twins in order that one should survive. In such cases, a very precise descriptive judgment regarding the situation is essential in order to justify the prescriptive judgment that must eventually be made.

In the case of recommendations, the descriptive part is by definition supposed to exist. As we said above with regards the fourth element of expertise, the expert is called upon only if some factual elements are at stake. For instance, an expert might suggest letting the government deficit increase during a recession, while expecting or encouraging a drop in the deficit during periods of growth: her prescriptions intimately depend on the way in which she perceives the factual context.

Hence all prescriptions do imply certain descriptive judgments, whether implicit or explicit.

(3c) Secondly, prescriptions imply certain evaluative judgments, even though these are not always clearly stated. Prescriptions imply some value judgment as to what is good, better, or acceptable in the precise context of the statement. This element is necessary in order for a prescription to hold, as Hume's guillotine entails. Some would argue that the requirement of the presence of value judgments in prescriptive statements is controversial. Based on a "naturalistic" view of evaluations - in Hare's words - or as a possible consequence of the D view elaborated below (see section 4), ethical or prudential judgments are considered as mere statements of fact, so that statements implying evaluations may nevertheless not be valueloaded. The normative-positive distinction fades away under such view, and one would be tempted to consider evaluations as belonging to a wider class of descriptions. I dispute that this conclusion correctly follows from the naturalistic view: 
that the scientist uses values as a scientific "ingredient" in his reasoning does not entail the total disappearance of the evaluative content as to what is good, better, acceptable, or prudent in the statements that result. Conversely, such value judgments, be they ethical or prudential, are necessary for the orientation of the prescription. Ideally, as we shall confirm below, if the person who formulates the prescription is not the person who requested it, such value judgments should reflect the client's values rather than the expert's values. Prescriptions are indeed a mix of descriptions, evaluations, and authority for action.

In the case of obligations vii or viii, there is an implied evaluative judgment that it is better not to drink, plus a sociological judgment that this evaluative judgment is a good thing to follow, and a psychological judgment that the prescription shall be followed. All in all, in the case of obligation, statements of sociological facts, psychological facts, and normative facts are necessary elements to build an overall prescriptive judgment. Under the previous example of judging the rightness of a public deficit by appeal to automatic stabilizers, the expert supposes that there exists an outside evaluative statement which says that it is good to use the state budget for macroeconomic purposes, and that it is good to stabilize economic conditions. If these premisses did not hold, quite apart from the knowledge of the theory of automatic stabilizers and of the actual shape of the economy, the expert would not be able to derive any recommendation, but would have to be content with mere descriptions. In the case of recommendations, it is necessary to have some idea of the likelihood that the principles under which the prescription is formulated would be well received by the client, as well as a statement of the value judgments.

(4) It now is time to summarize the conclusions we have reached so far, and conclude on the proper way to analyze value demarcation in expertise. Experts' prescriptions, which I here call recommendations, are not compulsory even where they comprise recommendations for action deriving from a mix of both descriptive and evaluative judgments. Description is the ground for neutral scientific work, 
and it contains a fortiori no value judgments. ${ }^{7}$ Nevertheless, among the scope of true assertions, the formulation of a descriptive judgment entails the responsibility of selecting, among all possible descriptions, the relevant one for the actual objective of this description. This selection task is called for by a distinct type of judgment - evaluation - which in turn has been selected in order to derive a prescription. In the case of expertise, these value judgments should be selected to correspond to the requests of the client to whom the recommendation is addressed. As prescriptions contain some value judgments, evaluation and, as a consequence, the primary description, can also be seen to contain them, by a process of reverse construction.

I have indeed described a decision process in successive stages. If one considers the construction of the decision from the beginning to the end, neither science nor description are value-loaded ${ }^{8}$. Demarcation seems possible at each of the first stages: the dichotomous model, which simply sets "is" and "ought", supposes a clear distinction between descriptive statements and statements implying value judgments. Yet, values are to be implicated by and incorporated in expertise, i.e. at the later stages of the decision process. As we have shown until now, these stages are logically dependent with each other. The fact that the expertise exists and directs the selection of values, makes the judgments developed at earlier stages value-loaded. Hence the judgments implied in earlier stage may have a different status because of later stages. I therefore claim that there is a feedback"retroaction" of values between stages coming from the later stages to the first ones.

I therefore suggest a move from a simple dichotomic model to another one, more sophisticated. The simple demarcation model supposes "is" and "ought" may be separate if you can distinguish descriptions from the rest of the process. My demarcation model supposes to take into account the interaction of the different stages of the process, and, in particular the feedback of the necessity of value judgments of the later stages to the kind of descriptions and theories we make at

\footnotetext{
${ }^{7}$ I do not adopt Myrdal's "science is ideology" position, as I shall argue in the last section.

${ }^{8}$ It would be more accurate to say they may be value-loaded under certain views, but this is not the issue at stake here. This point shall be partly discussed below.
} 
earlier stages. I now need to describe the decision process and makes an analysis on the basis of the specific analysis of each step of this process in a reverse order. This is what I shall do in section 3.

\section{Prescriptive judgments and expertise}

We now know that descriptive, evaluative, and prescriptive judgments depend on each other. A decision may or may not follow the prescriptive judgments; and the latter depend in turn on certain evaluative judgments, which themselves depend on a selection of certain descriptive judgments. As a consequence, if we are to understand where and how values are contained within the prescriptive judgments formulated by experts, an exclusive focus on experts' prescriptive judgments would seem to leave significant elements out of the analysis. We have seen previously that the value judgments used in a prescriptive judgment are logically connected with the description; we will be able to identify the way in which descriptions may incorporate value judgments by reconstructing this process in reverse. Value judgments are indeed ingredients not only of evaluative judgments, but also of descriptive judgments.

The decision process can be divided into six phases. Within the three broadest stages sketched in the introduction to this paper - the final decision phase, the expertise phase, and the primary stage, science - there are six phases to the decision process, which we may present in chronological order as follows: First comes (1) the scientific phase. The middle stage, expertise, contains four phases: (2) request, (3) selection of the model, (4) application to the data, and (5) formulation of a report, with descriptions, evaluations and prescriptions. The decision phase (6), which comes last, may include a political process in the case of a public decision. To take into account this interdependence of the three categories of judgments in the decision process, I propose to work backwards in order to reconstitute how the recommendation is arrived at. I therefore set out these six phases in reverse order and analyze their value-contents. 
The last phase of the decision process concerns the decision, properly speaking (6). The "client," e.g. the policy maker, uses information provided on the basis of economic expertise, or perhaps from a plurality of economic experts, to take his decision. As I noted in the previous section, he may have overriding reasons not to follow the prescription, and consequently may indeed not follow it. Just as prescriptions come from the expert, so the decisions come from the policy maker. Because of their distinctive attributes, prescriptions from experts are not compulsory for the clients. Reasons not to follow the recommendations made on the basis of expertise may emerge from the decision process itself, or from the divers persons comprising the client institution. Perhaps the public would not ratify the proposal whatever the arguments in its favor; or perhaps there are personal disagreements between certain persons, a lack of confidence in the expert, etc. The policy maker is the one who will eventually take the decision, and thus, in the end, is the one who is accountable. But saying that the decision pertains to the client does not yet entail that it is completely independent of the way the expert formulates her prescriptive judgment. The expert's judgments may indeed influence the client's decision. True independence would mean that experts would never influence the client's decision; but in such a case, the very fact that there had been a call for expertise appears odd. In the end, the decision is more likely to follow the recommendations than not; and at the very least, we cannot suppose that it is completely independent.

Let us now consider the different phases the decision process has to go through in the expertise stage.

In the final phase of the application of expertise (5), the expert is asked by the client to formulate a judgment. Here it is important to note that the expert is constrained to apply a selection from her knowledge to a selection from the relevant data. In so doing, she must make a choice from among a range of different analytical framings, each of which will conceptualize the situation in a different way. For instance, there are different models for explaining the links between unemployment and working time, and these respond differently to different initial assumptions. In view of the need to select from among the relevant data and ana- 
lytical frames, the task of formulation of an overall judgment comes to resemble an "art" of economics in the sense proposed by John Neville Keynes (1891), ${ }^{9}$ i.e., that the discipline decides on rules of practical action or evaluation on the basis of a profusion of theoretical and empirical economic knowledge. For demarcation to be preserved within the "art" of political economy, we must suppose, first, that knowledge belongs to the scientist, second that "judgment" or "prudence" belongs to the politician, and third - and most strongly - that the process of selecting data or models from such a plurality is never subject to any value bias. But this is unlikely. There is not, and nor could there be, any means of regulating the cognitive processes whereby we derive judgments from this plural and multifaceted foundation such that the potential for bias was excluded. The possibility of demarcation is therefore doubtful, due to the impossibility of disentangling the influence of values within the art of political economy.

The application of economic knowledge (4) is also part of the expertise stage. Here the expert applies selected knowledge to the data in order to formulate the answer to the client's request. This means she needs to locate (or generate) the relevant econometrics to derive the desired conclusions via confronting the data with the selected knowledge. To measure inequality, for instance, the expert who has primarily chosen to focus on income rather than other kinds of data, shall also have to choose certain data and certain normalizations from among the statistics. In other words, the expert has the responsibility of selecting some kinds of descriptive judgment among the many possible ones in order to frame the eventual recommendation. In the ideal dichotomy model, the choice of description among all consistent ones should depend on the client's aims and nothing else. If the latter are fuzzy, changing, or insufficiently specified, the expert would most likely make the selection independently. She would then bear some responsibility for the value content of the eventual prescription. This is another hindrance to the demarcation of the role of expertise, which we shall further develop below.

The expert also needs to select the relevant models (or any other kind of

\footnotetext{
${ }^{9}$ See below in the presentation of the (B) view.
} 
knowledge produced by economic science) to answer the request (3). Again, if the client's value judgements are sufficiently explicit, the expert will be able to take them into account and exclude any appeal to frameworks which might be in conflict with them. If they are non-explicit, or fuzzy, or insufficiently specified, the expert might need to appeal to her own "imagination," habits, or inclinations. In our example of measuring inequality, for instance, an expert may select the Gini index for incomes among the diverse inequality indices and diverse possible metrics. This might not be discussed with the client; perhaps it will merely be presented as a technical or pragmatic choice. Perhaps they will claim that the Gini index has appealing mathematical properties, or that there are available data sets for incomes, while these do not exist for standards of living. In the example of measuring inequality, the answer to the question "Has inequality increased since $\mathrm{x}$ ?" may thus be a yes or a no. Nevertheless, there is a diversity of possible analyses, and the expert might be well aware of these. In this specific case, conclusions would be different according to the choice of the index, the metric, and even the source of statistics. As Kolm has remarked:

"different measures of inequality give widely different, and even opposite, results. Such policy which diminishes some apparently reasonable measure increases other ones; And I can take any country and prove that in some period (whatever it is) inequality has increased or decreased in it, or any two countries and prove that inequality is higher in the one or in the other, by choosing different inequality measures, all of which would probably seem good and valuable at first sight. Furthermore, this embarrassing situation happens not only when we consider the complex social, or socioeconomic, or economic position of persons, or even their consumption-labor bundles over time or even timeless, but even in the simplest case where the variable is a unique magnitude (and, even a quantity) per person, such as its income or its wealth."10

\footnotetext{
${ }^{10}$ Kolm (1976a:416).
} 
The choice of an index, which may be made consciously and for pragmatic reasons, nevertheless implies a selection of certain values and a rejection of others. As we shall discuss with respect to step (1), further specific analyses of the value content of such a selection of knowledge may be of interest. In the case of inequality measures, this may be done straightforwardly thanks to the existence of systematic normative analyses of inequality indices. For other domains of economics we cannot consider that this may be so easily done on the basis of existing economic literature - it may not even be possible at all. Among other things, it would require the existence of an (independent) normative analysis of each of the models used. In such a case, the difficulty of associating explicit values to each model constitutes a second hindrance to demarcation.

We have until now supposed that the expert is willing to serve the public objective. But if her objectives diverge from those of her client, the process of selecting models or selecting data becomes a strategic tool. ${ }^{11}$ If the consequences of the recommendation for the expert run counter to her incentives to make proposals that are most helpful to the client - e.g. the risk of loss of reputation, or perhaps of losing opportunities for further consultancies or grants -, the expert may indeed have divergent objectives. ${ }^{12}$ Hence, her selection may serve her own rather than the client's values. The difficulty of controlling for the agency problem in client-expert relations forms a third hindrance to demarcation in expertise.

The application of expertise starts with the request (2), i.e. the appeal to expertise by an interested client. ${ }^{13}$ The notion of a "client" is not uncommon in economics, ${ }^{14}$ where it is used to describe the person, political authority, policy maker, etc., who uses economics as a tool.

In the simple dichotomy model, the value judgments should be issued by the client - meaning that he should formulate them explicitly. In other words, the

\footnotetext{
${ }^{11}$ See the seminal paper of Crawford and Sobel (1982) on a strategic exercise of expertise.

${ }^{12}$ See Gromb and Martimort (2007).

${ }^{13}$ Encinas de Munagorri and Leclerc $(2009,2010)$ develop the definition and the conditions of a request in the context of expertise.

${ }^{14}$ See especially Robbins' contributions, and e.g. Klappholz 1964:108.
} 
client should be able to furnish the elements of his utility function, i.e, his "ends," so that the economist can eventually derive the best "means" to achieve them, or to answer any of the expert's questions while respecting the client's value judgments, and without intruding with her own. Yet it is controversial whether this may in fact be done (e.g. when the client is an institution), or, if it can, whether it is possible in a very extensive range of cases. Returning to the example of measuring inequality, the question issued by the client would likely be: Has inequality increased or decreased since we were elected? In all likelihood, the clients would be unable to specify whether they wish to address the $\lambda$ or the $\mu$ condition of invariance, ${ }^{15}$ even though these denote respectively the rightist and the leftist inequality indices. ${ }^{16}$

Klappholz highlights another reason to be pessimistic as regards the possibility of the client being able to explicate her ends:

"Ends are not simply given, but are elicited and modified in the course of the discussion." 17

The difficulty of defining the client's ends or values constitutes a fourth hindrance to demarcation in expertise.

Let us now consider the primary, scientific, stage (1). We here speak of economic science itself, i.e. the production of abstract, empirical, and experimental knowledge regarding economic laws, axioms, theorems, models, etc. The study of the implication of values in scientific production can be conducted either by considering the role that values play within the produced economic knowledge values are an ingredient of economics and considered as such -, or by considering the role of individual values in the process of production of such economic knowledge - values have an influence in the way researchers in economics work, hence on their scientific results. On the one hand, economic science is supposedly

\footnotetext{
${ }^{15}$ For the $\lambda$ condition of invariance, multiplying the income of each individual by a strictly positive constant does not affect inequalities among them; for the $\mu$ condition of invariance, adding a given constant to each individual income does not affect inequalities among them.

${ }^{16} \mathrm{Kolm}(1976 \mathrm{a}, \mathrm{b})$.

${ }^{17}$ Klappholz (1964:110).
} 
descriptive. Some consider even normative economics to be a positive, scientific process, ${ }^{18}$ which deploys specific techniques in order to tackle value judgments treated as facts. For example, in the process of measuring inequality, the scientific stage consists in comparing the axiomatic analyses of the Gini, Atkinson-Kolm, Theil, or other inequality indices. Concretely, by distinguishing which axiom is respected or violated by each of the indices, we learn, for instance, how inequalityadverse, or left or right oriented, each one of them may be. ${ }^{19}$ At this stage, nothing justifies us in claiming that a researcher working on such abstract analyses should also hold the values expressed through the axioms. To give a trivial illustration, the use of an Atkinson index with $\varepsilon=0$ supposes the user is not inequality adverse, but this obviously does not imply that Anthony Atkinson himself is not inequality adverse. On the other hand, some carefully study the influence of individual values on the production of knowledge. I do not deny that personal values may influence the choice of the theme or content of the scientific production of any economist. Indeed, a great deal of evidence speaks in favor of this claim: this is sometimes explicitly assumed by the scientists themselves, and has also been documented in many contextual studies. But my claim is that this point is not relevant for our present inquiry. What is relevant here is to distinguish between the actual introduction of values (which is our subject), and the intention to introduce such values in a scientific work (or, conversely, to deliberately exclude them). Imagine that an economist has certain neutral intentions. They may well be value-impregnated, even if she is not conscious of this fact. Imagine now that the researcher has some value-loaded intentions which come into play in the process of producing scientific results. We must accept that the entirety of her scientific production does not explicitly result from these personal values, nor can we assert that her personal values are always well translated into the resulting scientific work. It is rarely easy for a scientist to consider all consequent impacts which her research may have; even though an analyst may ex post uncover her values in those impacts. In other words, there is no reason why we should trust that a

\footnotetext{
${ }^{18}$ E.g. Fleurbaey (1996); see the (D) view, below.

${ }^{19}$ See Gajdos (2001), Gajdos and Weymark (2012).
} 
researcher is actually doing what she thinks or claims she is doing.

Independent analyses might reveal that some of her assertions logically entail a certain ethical theory which appears to be contrary to the scientist's explicit intentions. For instance, Baujard (2010) showed that Bentham's ethical welfarism implies his prior commitment to fairness over goodness, contrary to the basic principles of his utilitarianism. In the case of the specific task of describing values - as in the case of the axioms of inequality indices -, I would label this production as neutral. In the other case described above, where the producer may, intentionally or unintentionally, incorporate values, the value content needs to be uncovered by further analysis. The value content of what I shall call "the primary scientific production", i.e. before it may be scrutinized for values, is undefined. The production may thus be labeled value-free in sense (D) (below). Such reflexive analysis is not easy to produce, in the sense that we cannot count on applying one method to produce a single paper for each family of models and consider that the value analysis is now done. A difference in context may indeed modify the normative analysis. ${ }^{20}$ Hence it might be necessary to study primary scientific production in a range of particular cases. There is hence no reason to suppose that the assertions of economic science, qua part of basic science and hence with no specific purpose and not contextualized, should be generally labelled as either neutral or non-neutral. To be able to assess the value content of an economic statement, it must be considered in conjunction with other contributions.

As a consequence, the value content of expertise cannot be identified in just considering each economic assertion used to derive an expert recommendation, but requires further information. In order to demarcate the role of expertise, the expert will need to address three things.First, she must identify the client's values. Second, she must provide a primary scientific production, which of course we cannot consider neutral a priori. Third, she also has to show that she has scrutinized this production for traces of values which may be relevant to the specific context of this expertise. As we can now see, the normative analysis of the pri-

\footnotetext{
${ }^{20}$ See notably the analysis of rankings of opportunity sets by Baujard $(2007,2011)$ with respect to considering the role of contextual features on the conception of freedom.
} 
mary scientific production only makes sense via feedback, i.e. because it is used in a given context in a process of expertise where values are involved. A fifth hindrance to the demarcation of value judgments in the application of economic expertise lies in the absence of systematic theoretical analyses of the normative content of theoretical models (and data) in different possible contexts within the realm of economic science.

As an interim conclusion, we may say that the presentation in reverse order of the process of framing scientific knowledge, expert judgments, and decisions, allows us to see the interdependency between the different stages, and hence to consider in a more precise manner where value judgments may be involved at each step. Can we now draw any conclusions as regards the normativity, or conversely the value neutrality, of expertise?

Against the thesis that recommendations based on economic expertise have a normative content, I have argued that prescriptions are not compulsory; that the client's decision is not dictated by the expert. Conversely, in favor of the thesis of normativity, respecting the allocation of tasks does not prevent the expert's values having substantial influence on the decision. I have described a number of serious hindrances to the demarcation of value judgments in the application of economic expertise, such that the client cannot disentangle the values involved in the recommendation which is supposed to inform the final decision. The latter depends on the expert's choices, and not just on her scientific knowledge or any non-valuebased choices. Hence the expert is not just a neutral transmitter of knowledge from the realm of science to reality. She does unquestionably incorporate values in the process of formulating a prescription, and the resulting decision may be influenced by these values.

\section{Positions on demarcation in economic expertise}

This section sets out a categorization of the different positions which may be adopted with respect to the demarcation of value judgments in the application 
of economics expertise to practical problems. That is, these are theses concerning the relative scope of neutrality and normativity within the different demarcation schemas that are available. Mongin (2006) proposed a seminal typology of neutrality theses in economics, which is summarized in table 1 . Reference to this original paper shall prove necessary in order to understand what is at stake in this discussion, but in so far as I consider the particular case of prescriptive judgments to be recommendations which follow upon the application of expertise, and thus concern not only the problem of possibility but also that of legitimacy, I shall here need to modify his presentation. This organization is summarized in table 2 . Cases of correspondences with Mongin's typology are specified on the right.

Table 1 Typology of neutrality theses, according to Mongin (2006). Can economists avoid value judgments?

I- According to the strong neutrality thesis, all economics is positive.

II- According to the weak neutrality thesis, there are inevitably some value judgments, but they can be made explicit and so contained.

III- According to the strong non-neutrality thesis, value judgments can never be disentangled from others.

IV- According to the weak non-neutrality thesis, certain value judgment can be disentangled from others, and some cannot be.

(A) The position that there exist both a positive economics and a normative economics corresponds to the famous dichotomy of normative $v s$. positive as notably introduced by J. S. Mill. This is based on the same grounds as the common opposition between ethics and science, is and ought, and facts and values. Hume's Guillotine has been called upon to help us understand the scope of the distinction. ${ }^{21}$ According to Hume, you cannot deduce an "ought" from exclusively "is" premises. A normative economics based on value judgments, as well as a clearly separated positive science of economics, both on this view fall within the purview

\footnotetext{
${ }^{21}$ Note though that the textual reference to Hume was incorporated into the standard reference of economics methodology only lately, after Robbins' book (Mongin 2008: 3[34]). The retrospective reconstruction is therefore most likely an anachronism, but it makes sense today to clarify the distinction at stake.
} 
Table 2 Typology of areas of economics and positions on neutrality.

Should economists make value judgments; or, can experts legitimately make value judgments?

Economics' areas:

A- Both a positive and a normative economics exist;

B- Besides normative and positive economics, a particular branch of economics determines the practical rules of action;

Positions towards neutrality:

C- Economics should be neutral;

D- Economics is entirely neutral ;

E- Economics is entirely non-neutral;

F- Economics cannot be entirely neutral.

of the economist. With respect to the normative part, though, some consider that value judgments should nevertheless be kept to a minimum. Mongin calls this position "the containment claim" (as developed in his position II). In general, normative economics should just be concerned with certain value judgments, standardly the Pareto criterion, whether interpersonal comparisons of utility are accepted or not, and equality. ${ }^{22}$ According to this position, economics proposes different kinds of scientific analyses: on the one side mainly based on facts (as well as logic and mathematics), on the other mainly based on values (again, as well as logic and mathematics). Since the distinction between "is" and "ought" is often called upon to make this clear, two notions of "ought" should here be distinguished (as we did above in section 2: 3a). On the one hand, there is an "ought" which just corresponds to an evaluative judgment, something which normative economics as a theoretical device standardly cares about. On the other hand, there is an "ought" which corresponds to a prescriptive judgment, i.e., a rule of action, which may be either imperative or not, as are recommendations in the case of expertise. In the context of expertise, where the problem at stake calls for prescription and not just evaluation, something more is necessary than simply a normative economics

${ }^{22}$ Bergson 1938, Samuelson 1947, Little... 
focused on ought as "evaluation." This is why I now consider a second way of classifying the areas of economics, one which is more likely to correspond to the specificity of prescriptions.

(B) On this view, besides normative and positive economics, economics is also concerned with the "determination of practical rules of action." Whereas this position is a subdivision of (II) in Mongin's (2006) account, drawing out the latter activity allows us to seriously consider the specificities of prescriptive judgments, and to tackle the subject of expertise itself. The traditional presentation of political economy in the late nineteenth century and at the beginning of the twentieth is based on a trichotomy of normative economics, positive economics, and the art of political economy. John Neville Keynes's famous quote is often called upon to define the latter:

"As regards the scope of political economy [...], does it treat the actual or the ideal? Is it a positive science concerned exclusively with the investigation of uniformities, or is it an art having or its object the determination of practical rules of action? [...] The first belongs to positive science, the second to normative or regulative science (along with ethics, if indeed it be not a branch of ethics or of what may be called applied ethics), and the third not to science at all in the more modern use of the term, but to art as distinguished therefrom. [...] A positive science may be defined as a body of systematized knowledge concerning what is; a normative or regulative science as a body of systematized knowledge relating to criteria of what ought to be, and concerned therefore with the ideal as distinguished from the actual; an art as a system of rules for the attainment of a given end. The object of a positive science is the establishment of uniformities, of a normative science the determination of ideals, of an art the formulation of precepts. [...] "23

Art is not part of economic science strictly speaking. But this is the subset of

\footnotetext{
${ }^{23}$ Keynes, J. N. (1891:20, 22-23, italics in original text)
} 
political economy which is of interest for the decision-maker. Demarcation is obviously not easy to maintain within the art of political economy, as we claimed above.

Now we can develop a typology of positions as regards demarcation.

(C) "Economics should be neutral." This claim is one of the justifications of the strong neutrality thesis (I), according to Mongin (2006). This position notably corresponds to the Weber's notion of value-neutrality, his Wertfreiheit: normative assertions belong to politics, not to economics. The rationale of this position is the following: Values do exist, but as they cannot be proven on scientific grounds, they lie outside the scope of science. In so far as it remains a science, a special effort appears necessary to place a border between economics and non-scientific assertions, including ethical statements. Hence economists qua economists should not make value judgments. A famous representative of this position is Lionel Robbins: he focuses on the specific case of interpersonal comparisons of utility that are, in his mind, obviously not value-free.

\begin{abstract}
"An interpersonal comparison of utility is a comparison which is never needed in the theory of equilibrium and which is never implied by the assumptions of that theory. It is a comparison which necessarily falls outside the scope of any positive science. [...] It involves an element of conventional valuation. Hence it is essentially normative. It has no place in pure science." 24
\end{abstract}

According to this position, demarcation within science even goes beyond the distinction between the roles of economists as scientists and the role of citizens - or their representatives. The latter are decision-makers who may deal with values; the former deal with facts only. A consideration of the mix of facts and values belongs to the art of political economy, but not to economic science as such. Ruling any "ought" out of the scope of economics (and interpersonal comparisons of utility in particular) has a troubling consequence: it definitively excludes the

\footnotetext{
${ }^{24}$ Robbins (1932:130)
} 
possibility that economic science can develop recommendations. This element is thus linked to the pessimistic and persisting view - yet controversial - that "welfare economics is dead." 25 Fortunately, considering values to be outside the scope of science does not prevent prescriptions being made for their own sake: experts' prescriptions remain viable. Unfortunately, this restriction of economic science to facts has another troubling consequence: prescriptions are now made without any scientific precaution nor any special care for value transparency, thus raising the question of demarcation in the domain of expertise. My claim is therefore that position (C) amounts to sweeping the demarcation issue under the carpet, but not resolving it.

(D) "Economics is entirely neutral." This view corresponds to a second justification of the strong neutrality thesis (I), according to Mongin (2006). ${ }^{26}$ Of course, values do exist, but they may be considered to be scientific objects, just as prices or quantities are. Hence scientific assertions may equally well concern values or facts. This view, well represented by social choice theory or negotiation theory, is explicitly defended by Fleurbaey:

"The domain of the economic theories of justice, that is tackled by this textbook, belongs to positive economics, and does not contain any normative or prescriptive assertion! [...] Positive, in the meaning we retain here, does not just concern descriptions of phenomena, but also includes the study of claims and lines of arguments." 27

This position supposes a strong belief in the possibility of demarcation, along with the following principle: the economist makes value judgments in so far as she herself holds the values which are the object of her judgment; but she makes positive assertions in so far as she considers value judgments that are held by somebody

\footnotetext{
${ }^{25}$ Baujard (2011)

26“"The naturalistic view," Hare (1952) refers to may be considered as a subcase of this thesis.

27 "Le domaine des théories économiques de la justice, dont traite le présent ouvrage, appartient à l'économie positive, et ne contient pas d'assertion normative ou prescriptive ! [...] Le positif, dans l'acception proposée ici, ne concerne pas seulement la description des phénomènes, mais englobe également l'étude des arguments et des raisonnements." Fleurbaey (1996:2), my translation
} 
else. Can we apply this view directly to our aim of assessing the possibility of demarcation within expertise? Certainly not: it is strictly concerned with economic theory or economic science as such, but cannot be extended without further qualification to any applications. Once applied, we are led to question the allocation of tasks between the decision-maker - who holds the value judgment - and the expert - who uses it in her framework to answer the question posed by the former. In this case, we shall need to move to another view of demarcation.

(E) "Economics is entirely non-neutral." This view corresponds to the strong non-neutrality thesis (III) in Mongin's typology. Myrdal's (1954) position illustrates this view. ${ }^{28}$ In a wider sense, this view is held by neo-Marxists and many heterodox economists. According to this view, value judgments and judgments of facts cannot be logically separated. Hence, if not ideology, then values at least cannot be disentangled from the so-called scientific assertions. Myrdal comments as follows:

"A disinterested social science has never existed and, for logical reasons, cannot exist. The value connotations of our main concepts represent our interest in a matter, give direction to our thoughts and significance to our inferences. It poses the questions without which there are no answers. [...] The recognition that our very concepts are valueloaded implies that they cannot be defined except in terms of political valuations. It is indeed on account of scientific stringency that these valuations should be made explicit. They represent value premises for scientific analysis; contrary to widely held opinions, not only the practical conclusions from a scientific analysis, but the analysis itself depends necessarily on value premises." 29

As demarcation is impossible according to this view, economics, whether considered qua science or expertise, is entirely normative. The worst we can do on this account is to place a veil over value judgments - or to allow such a veil to be

\footnotetext{
${ }^{28}$ For a more nuanced account of Myrdal's position, see Bellet and Barbaroux (2012).

${ }^{29}$ Myrdal (1958:1)
} 
placed. Conversely, it becomes encumbent on us to identify the value judgments: transparency is a deontological requirement of the discipline, which requires us to organize a "technology" of demarcation at each step of the construction of an economic assertion.

(F) "Economics cannot be entirely neutral." This corresponds to the weak non-neutrality thesis (IV), which is the one defended by Mongin (2006). Certain value judgments can be disentangled from others, in which case neutrality can be retained. But this is not always logically possible, in which case economists can no longer claim to be value neutral. This is also the view I defend for the case of economic expertise. Let us develop it.

I have shown above that there are various reasons why demarcation is not always possible. Let us recall them here, though in a different order. Because of the interdependency of the different stages of the decision process, analyses of demarcation focused on economic science may be marked by the problem of demarcation as it occurs in the context of expertise. First, the expert is responsible for the art of combining models, but there is no framing procedure for this art that is likely to be able to control demarcation. Second, concrete evaluation entails the selection of a description: the expert needs to choose some operational meaning and statistical content in order to formulate the specific evaluation she is expected to make. If the value in question were different, then her choices would have to be adapted accordingly. Because evaluations imply values, this selection is consequently value-loaded. Similarly, the selection of one model or framework from among the existing ones is also a determining choice, which incorporates values. Third, even if the explication of values were theoretically possible, it remains concretely difficult, if not impossible, for the client to list all his given value criteria. Fourth, it might be difficult to associate an explicit value to each model, at least because of the importance of context. The absence of systematic analyses of the normative content of theoretical models in different context does not help. Fifth, it is not always obvious how to control for the agency problem. Because of these problems, values incorporated into the decision do not only come from the client, but may well be influenced by the person working as an expert. 
The four views and associated problems are summarized in table 1 . The simple Table 1: Explicit and implicit values

\begin{tabular}{|c|c|c|c|}
\hline \multicolumn{2}{|c|}{} & \multicolumn{2}{c|}{ Client } \\
\cline { 3 - 4 } \multicolumn{2}{|c|}{} & Explicit & Implicit \\
\hline \multirow{2}{*}{ Expert } & Explicit & Case EE & Case IE \\
\cline { 2 - 4 } & Implicit & Case EI & Case II \\
\hline
\end{tabular}

dichotomy model, according to which demarcation is possible (as in views (C) or (D)), supposes we are always in case EE: both the value judgments held by the client and those held by the expert are unambiguous. Conversely, the strongneutrality view (E) not only supposes that experts have implicit values - i.e., that we are always in cases EI or II, and that it is most likely that we are in case II -, but also that there is no way through which we can expect to reduce such ambiguity. View $(F)$, which I here defend, considers that all four cases are likely to happen, according to the specific situation in question.

The analysis provided above allows us to enumerate some paths which may help us at least to reduce the scope of the demarcation problem, although perhaps not to remove it altogether. Let us consider these cases of ambiguity.

When the client fails to state explicit values, the expert could be required to question him until he makes them explicit. A policy-maker who is used to thinking or pretending that the statistics speak for themselves will likely not be able to give a specific account of his values as regards distributive justice when he asks the expert to measure inequality. By contrast, the expert knows (or, at least, should know) which values are relevant to chosing among the available economics tools and statistics. Before accepting the demandrequest, she thus has a responsibility to ask for an explication of which values are relevant and why, and to require this to be specified in the contract.

Experts may have implicit values for different reasons. If the ambiguity is intentional, there is a deontological issue at stake that no methodological improve- 
ment within economics itself can resolve; this will turn on matters such as reputation, or a solution to the agency problem which includes the reward system and the legal responsibility of the person acting as expert. However, ambiguity is not necessarily intentional, for the expert may simply be unaware that their economics tools are value-loaded. This may be interpreted as a result of her poor knowledge, which could thus be compensated for by better education or by the selection of experts on the basis of their training. But, as we have argued above, the lack of awareness might come from economic science itself, particularly in the absence of a reflexive science apt to scrutinize the value content of economic production in the relevant context. There is therefore a need for more systematic normative analysis of existing work. Besides, within the art of political economy, there is not to my knowledge any reliable way to organize the process of the selection of models, and the process of framing judgements on the basis of such models, which could allow for the intrusion of value judgments to be controlled. As much of the value-loaded activity may not be subject to a systematic process of demarcation, the selection of the expert who shall incorporate these values constitutes the primary and determinant value-loaded choice, here taken by the client. In this respect, certain procedures may be called upon to facilitate this process, e.g. procedures of selection of experts (Leclerc 2005, Leclerc and de Munagorri 2010) which describe their values, their educational training, and previous attachments to certain institutions, which might be an indirect means by which to approximate the determinants of such a cognitive process.

It is worth specifying that the view $(\mathrm{F})$ purposes to retain the view contained in (B) of distinctions between areas within economics, rather than the now more standard view contained in (A). Within (B), positive economics should not be developed without any consideration of what is at stake in the context of "the art of political economy." This is one of things which is at stake in opening up the debate on demarcation. Analysis of demarcation in economics is standardly focused on economic science; here I have chosen to consider it within the whole process stretching from production of knowledge up to its use in producing expert advice, and the eventual decision. It is important to understand why the latter emerges as 
essential for the actual analysis of demarcation in economics. I can accept that the normative status of some scientific assertions in economics may be undefined. But, I claim, they do not remain undecided forever: at some point in a decision process involving economic science values may be identified, and this can then be seen as bearing implications, via a process of backwards reasoning, for the first stage of its production. The analysis I have here conducted of the properties of descriptive, of evaluative, and of prescriptive judgments, as well as the enumeration of the stages of production of knowledge, expertise, and decision, allows us to understand the irreducible interdependency between the production of economic knowledge and of economic expertise. Of course, theorists generally do not apply their theories themselves; they may not even control the way in which they are used. Economists who produce value-loaded theories become responsible for their values when their theories are applied, because that is the moment when these values become influential - and, even more so, because it is the raison d'être of their theoretical production that the theories they produce are likely to be applied. It is therefore not at all clear that theorists are entitled to wash their hands of value analysis once their theories pass into use within public policy.

\section{Conclusion}

In the ideal dichotomy model, positive economics is considered to be separate from normative economics, and demarcation is supposed to be based on a perfect division of tasks between the client and the expert. This division entails the possibility of clearly distinguishing between "is" and "ought," or "facts" and "values," in every economic assertion, whether these be theoretical or applied claims. The client provides information on his "values," and the expert integrates them as an ingredient in her scientific and otherwise value-neutral reasoning, from which she will derive a prescriptive judgment.

Yet, as this paper showed, the dichotomy model is unstable, since, at each step of the framing of the expert's recommendation, the demarcation between value 
judgments and neutral scientific assertions is not straightforward. In this paper I conducted a backwards analysis of the process of production of prescriptive judgments in order to show that such judgments imply certain value judgments not only for sheer logical reasons, but also as a result of the interdependence between descriptive, evaluative, and prescriptive judgments. Since the reasons for this are summarized in the description of view (F) defended above, I shall not repeat them here. This paper studied the difficulties of maintaining a strict demarcation of values in the case of economics expertise. The results of scrutiny raise three broad conclusions, with which I close. First, these difficulties entail that, in addition to the distinction between positive and normative economic science, there exists within political economy a third discipline, the art of diagnosis of the situation and design of rules for action, which is still to be built. Second, these difficulties raise a general and serious problem: the issue of legitimacy of decisions based on an appeal to expertise within a democratic setting. In order to guarantee the legitimacy of the scientist's intervention in the realm of prescription, are there any methodological improvements which could be made within economics which may help to ensure proper demarcation, or at least transparency? As we reflected above, this is an intractible problem, notably within the art of political economy. But the scope of the problem can be reduced if systematic analyses of the value of economic models in diverse contexts are conducted, and if theoretical attention is paid to the consequences of the selection of certain data or normalization techniques. Hence, and finally, the study of the role of economic expertise in the framing of public policy decisions could have important consequences for the way economic science may develop.

\section{References}

[1] Andrews, D. The background to Hawtrey's ethics. History of Political Economy 42, 2 (2010), 297 - 322.

[2] Archibald, G. C. Welfare economics, ethics, and essentialism. Economica 26, 104 (1959), pp. 316-327. 
[3] Arrow, K. J. Social Choice and Individual Values. John Wiley \& Sons, New York, 1951.

[4] Balisciano, M. L., And Medema, S. G. Positive science, normative man: Lionel Robbins and the political economy of art. History of Political Economy 31 (1999), 256 - 284.

[5] BAujard, A. Conceptions of freedom and ranking opportunity sets: A typology. Homo Oeconomicus 24, 2 (2007), 231-254.

[6] BAujard, A. Collective interest vs. individual interest in Bentham's felicific calculus. Questioning welfarism and fairness. The European Journal of the History of Economic Thought 17, 4 (oct. 2010), 607-634.

[7] BAUjARD, A. L'économie du bien-être est morte. Vive l'économie du bienêtre ! Working Papers CREM 2011-02, 'Public Economics and Social Choice' Series, june 2011.

[8] Baujard, A. Utilité et liberté de choix dans les classements d'ensembles d'opportunités. Raisons Politiques, 43 (Août 2011), 75-108.

[9] Bellet, M., AND Barbaroux, N. Monetary policy and value judgments: Did we forget Myrdal's legacy? Working Paper, GATE L-SE, 2012.

[10] Blaug, M. La méthodologie économique. Cambridge Surveys of Economic Literature. Economica, 1980. seconde édition 1992, 1995.

[11] Boulding, K. E. Economics as a moral science. The American Economic Review 59, 1 (1969), pp. 1-12.

[12] Buchanan, J. M. Positive economics, welfare economics, and political economy. Journal of Law and Economics 2 (1959), pp. 124-138.

[13] BURK, A. A reformulation of certain aspects of welfare economics. The Quarterly Journal of Economics 52 (1938), 310-334.

[14] Crawford, V., AND Sobel, J. Strategic information transmission. Econometrica 50, 6 (1982), 1431-1451.

[15] DaVis, J. B. Robbins, textbooks, and the extreme value neutrality view. History of Political Economy 37, 2 (2005), 191 - 196. 
[16] Encinas De Munagorri, R., And LeClerc, O. Théorie du droit et expertise : Conclusion prospective sur les apports de l'analyse juridique. In $E x$ pertise et gouvernance du changement climatique, R. Encinas de Munagorri, Ed. LGDJ, coll. « Droit et société », tome 51, Paris, 2009, pp. 199-229.

[17] Encinas de MunagorRi, R., And Leclerc, O. Les apports de la théorie juridique à la délimitation de l'expertise. réflexions sur le lien de droit. In Aux frontières de l'expertise, Y. Bérard and R. Crespin, Eds. Presses Universitaires de Rennes, coll. « Res Publica », Rennes, 2010, ch. 10.

[18] Fleurbaey, M. Théories économiques de la justice. Économie et Statistiques Avancées. Economica, 1996.

[19] Gajdos, T. Les fondements axiomatiques de la mesure normative des inégalités. Revue d'économie politique 5 (2001), 683-720.

[20] Gajdos, T., AND Weymark, J. Introduction to inequality and risk. Journal of Economic Theory, Symposium on Inequality and Risk 147 (2012), 1313-1330.

[21] Gromb, D., AND Martimort, D. Collusion and the organization of delegated expertise. Journal of economic theory 137 (2007), 271-299.

[22] HARE, R. M. The language of morals. Clarendon Press, Oxford, 1952.

[23] Hausman, D. M., Ed. The philosophy of economics. An anthology. Cambridge University Press, New York, 1984. Version 1990.

[24] Heath, W. C. Value judgments and the principles of economics textbook. Southern Economic Journal 60, 4 (1994), pp. 1060-1064.

[25] Hennipman, P. Pareto optimality: Value judgment or analytical tool? In Relevance and precision: Essays in honour of Pieter DeWolff, A. H. Cramer, J. S. and P.Venenkamp, Eds. Samson, North Holland, Amsterdam, 1976, pp. 39-60.

[26] Hill, R., And Myatt, A. The Economics Anti-Textbook: A Critical Thinker's Guide to Microeconomics. Fernwood publishing, Black Point (Canada), 2010. 
[27] Keynes, J. N. Scope and method of Political Economy, 1917, 4ème ed. MacMillan, London, 1891. Reèd. in D. M. Hausman, Ed. The philosophy of economics. An anthology, Cambridge University Press, chap. 2, pp. 70-98, 1984 (1st ed.).

[28] Klappholz, K. Value judgments and economics. In British Journal for the Philosophy of Science [23], pp. 97-114. Reèd. in D. M. Hausman, Ed. The philosophy of economics. An anthology, Cambridge University Press, chap.14, p.276-292, 1984.

[29] Kolm, S.-C. Unequal inequalities. I. Journal of Economic Theory 12 (1976), 416-442.

[30] Kolm, S.-C. Unequal inequalities. II. Journal of Economic Theory 13 (1976), 82-111.

[31] LeCLERC, O. Le juge et l'expert. Contribution à l'étude des rapports entre le droit et la science. No. 443 in Coll. Bibliothèque de droit privé. LGDJ, Paris, 2005. Pref. A. Lyon-Caen.

[32] Martimort, D. La société des experts. une perspective crtitique. In Faire des sciences sociales. Critiquer, P. Haag and C. Lemieux, Eds. Editions de l'EHESS, Paris, 2012, pp. 209-235.

[33] Mongin, P. Value judgments and value neutrality in economics. Economica 72 (2006), 257-286.

[34] Mongin, P. Robbins and the separation of economics and ethics. Cowles Foundation Working Papers, 2008.

[35] Myrdal, G. Implicit values in economics. In Hausman [23], 1954. Extrait et reèd. par D. M. Hausman, Ed. The philosophy of economics. An anthology, Cambridge University Press, sous le titre : "Implicit values in economics", chap. 12, p. 250-259, 1984.

[36] Myrdal, G. Value in social theory. Routledge, London, 1958. Ed. and intr. by P. Streeten.

[37] NG, Y.-K. Value judgments and economists' role in policy recommendation. The Economic Journal 82, 327 (1972), pp. 1014-1018. 
[38] Robiins, L. An essay on the nature and significance of Economic Science, 3ème ed. Macmillan, London, 1932.

[39] Samuelson, P. A. Foundations of Economic Analysis. Harvard University Press, Cambridge, 1947.

[40] SEn, A. K. The nature and classes of prescriptive judgments. The philosophical quarterly 17, 66 (1967), 42-62.

[41] Sen, A. K. Description as choice. Oxford Economic Papers 32, 3 (1980), 353-369.

[42] Storbeck, O., And Hess, D. An interview with Amartya Sen: There is a democratic failure in Europe. Handelsblatt; English version available on: http://economicsintelligence.com/2012/04/12/an-interview-withamartya-sen-there-is-a-democratic-failure-in-europe/, 2012.

[43] Williams, B. Ethics and the limits of philosophy. Harvard University Press, Cambridge, MA, 1985. 